Diabetologia 7, 409-413 (1971)

(C) by Springer-Verlag 1971

\title{
A Quantitative Study of Peripheral Arterial Calcification and Glucose Tolerance in Elderly Diabetics and Non-Diabetics
}

\author{
B. NeUbauer \\ Second Clinic of Internal Medicine (Head: K. Lundbæk, M. D.), and Roentgen Diagnostic Department (Head: \\ E. Mosekilde), Kommunehospitalet, Århus University School of Medicine, Arhus, Denmark \\ Received, April 21, 1971, accepted: August 5, 1971
}

Summary. A quantitative study of peripheral arterial calcification and glucose tolerance in elderly diabetics and non-diabetics has been performed. A correlation between radiological media calcification and glucose tolerance in non-diabetics was found. Intima calcification was not correlated. Severe media calcification was much more common in diabetics than in non-diabetics.

Etude quantitative de la calcification artérielle périphérique et de la tolérance au glucose chez les diabétiques âgés et les non-diabétiques

Résumé. L'étude quantitative de la calcification artérielle periphérique et de la tolérance au glucose a été faite chez les diabétiques êgés et les non-diabétiques. II en est ressorti une corrélation entre la calcification de la tunique moyenne en radiologie et la tolérance au glucose chez les non-diabétiques. Il n'y a pas ou de corrélation avec la calcification de la tunique interne. Uno grave calcification de la tunique moyenne se rencontre plus souvent chez les diabétiques que chez les non-diabétiques.

Eine quantitative Untersuchung über die Calcifikation peripherer Arterien und die Glucosetoleranz bei älteren Diabetikern und Nicht-Diabetikern

Zusammenfassung. Es wurde eine quantitative Studie über die Verkalkung peripherer Arterien und die Glucosetoleranz bei älteren Diabetikern und Nicht-Diabetikern durchgeführt. Dabei wurde eine Korrelation zwischen der radiologisch feststellbaren Mediaverkalkung und der Glucosetoleranz bei Nicht-Diabetikern gefunden. Die Intimaverkalkung zeigte keine Korrelation. Schwere Mediaverkalkungen waren viel häufiger bei Diabetikern als in Nicht-Diabetikern.

Key words: Glucose tolerance, diabetic calcification, arterial calcification, radiological calcification, extremital calcification.

\section{Introduction}

Epidemiological studies of glucose tolerance from many countries over the last 20 years have shown that in grown-up people and especially in elderly people, there is no sharp distinction between diabeties and non-diabetics. The practical clinical diagnosis of diabetes mellitus is based on an arbitrary choice of a cut-off point in combination with the presence of diabetic symptoms.

Diabetic angiopathy can be diagnosed in all or nearly all diabetic patients after the disease has lasted a number of years. It has not been settled whether vascular abnormalities in the diabetics are secondary to a long period of abnormal carbohydrate meta bolism, or whether it is a concomitant phenomenon, developing slowly over the years; but at the present time the first hypothesis seems the more plausible.

It is established, however, that diabetic retinopathy is present in $4-5 \%$ of newly diagnosed diabetics [16], and the risk of developing retinopathy in the first years is higher in older diabetic patients than in younger [6]. It might be thought, therefore, that mild diabetes or "latent" diabetes which is found in a large percentage of elderly people at diabetes surveys, is accompanied by diabetic angiopathy in a certain number of cases. The mild diabetic state is symptom- less and at the moment it is accidently discovered, it may have been present for any number of years.

The term diabetic angiopathy usually includes retinopathy, nephropathy, perhaps cardiopathy [14] and possibly neuropathy as a clinical phenomenon [9]. In these cases the vascular abnormalities are located in the smallest vessels and in capillaries; and it is known from many studies that "microangiopathy" of the same morphological type as that found in the eyes, the kidney, the nervous system, and the heart is found in most other organs in long-term diabetes.

It is known from clinical experience that abnormalities of the larger vessels, e.g. the coronary arteries and the arteries of the extremities, are much more common in diabetics than in non-diabetics. This "macroangiopathy" of diabetics has not attracted much attention and has usually been interpreted as "a predisposition to arteriosclerosis in diabetes mellitus". Allan [1] states that the atheromas and the extensive calcification and destructive changes in the medial coat of the arteries in middle-aged diabetics are frequently similar to the changes found in the arteries of senile non-diabetics. However, a recent roentgenological study by Ferrier [10] has indicated the questionable character of this form of reasoning, by showing that the arterial disease in diabetes does not usually show the spotted type of calcification typical of 
arteriosclerosis, especially in old men, but rather the linear type of calcification which is the roentgenological equivalent of media sclerosis.

The present paper is a report of a study of glucose tolerance and $x$-ray calcification in the legs in elderly persons with and without clinical diabetes.

\section{Material and Methods}

The study includes 211 cases, 118 diabetics and 93 non-diabetics, between 50 and 90 years of age.

Non-diabetics were selected either from the outpatient clinic or among afebrile hospital patients who were up and about. They had no glucosuria and no diabetic symptoms. Patients with endocrine disease, liver diseases, or polyarthritis were excluded.

The distribution in age- and sex-groups is shown in table 1. With the age-intervals selected, the groups contain about the same number of cases.

Table 1. The age distribution of men and women in the series of diabetics and non-diabetics

\begin{tabular}{|c|c|c|c|c|c|c|}
\hline \multirow[b]{2}{*}{ Age } & \multicolumn{3}{|c|}{ Diabeties } & \multicolumn{3}{|c|}{ Non-diabetics } \\
\hline & $\overline{\text { Men }}$ & Women & Total & $\overline{\text { Men }}$ & Women & Total \\
\hline $50-57$ & 9 & 14 & 23 & 10 & 18 & 28 \\
\hline $58-64$ & 13 & 18 & 31 & 14 & 8 & 22 \\
\hline $65-71$ & 18 & 18 & 36 & 12 & 12 & 24 \\
\hline 71 & 9 & 19 & 28 & 6 & 13 & 19 \\
\hline Sum & 49 & 69 & 118 & 42 & 51 & 93 \\
\hline
\end{tabular}

Glucose tolerance test was performed in the morning after 12 hours fast and after withdrawal of insulin lente for $24 \mathrm{~h}$, insulin retard for $48 \mathrm{~h}$, oral antidiabetics for $36 \mathrm{~h}$ and thiazides for $24 \mathrm{~h} .70 \mathrm{~g}$ of glucose was given orally in $250 \mathrm{ml}$ water with $20 \mathrm{ml}$ of fresh lemon juice.

During the test the patient was sitting in an armchair in the parlour of the department, doing needlework, reading, or talking. Smoking was not allowed.

The administration of the glucose solution and the taking of the blood samples from the ear-flap were done by the author. Drinking-time was $2 \mathrm{~min}$. The blood samples were taken between 30 sec before and $30 \mathrm{sec}$ after time.

Blood glucose was determined immediately after the test with a glucose oxidase method (KABI).

Quantitative x-ray studies were performed by measuring the arterial calcifications on $x$-ray films, taken with low voltage technique. Seven suitable projections, chosen to make visible the whole femoral artery and its raminifications, were made on each patient. The exposures were taken according to a prefixed system, determining the position of the patient and of the casette, the localization of the central beam, and the exposure data (Table 2). However, each film was studied by the author immediately after being taken, and one or several new exposures were made after rearrangement of the geometrical situation if the part of the artery to be studied was not optimally visible.

All exposures were made with the same $x$-ray apparatus ${ }^{1}$. Focus was $1.2 \mathrm{~mm}$, focus film distance $130 \mathrm{~cm}$. The central beam was at right angles to the object.

Table 2. General outline of x-ray exposures for various parts of the femoral artery and its ramifications

\begin{tabular}{|c|c|c|c|}
\hline Object & $\begin{array}{l}\text { Position of } \\
\text { patient }\end{array}$ & $\begin{array}{l}\operatorname{Exp} \\
\mathrm{Kv}\end{array}$ & $\mathrm{mAs}$ \\
\hline $\begin{array}{l}\text { A. femoralis' } \\
\text { proximal part }\end{array}$ & $\begin{array}{l}\text { On the back. } \\
\text { Knee extended. } \\
\text { Foot vertical. }\end{array}$ & 56 & 60 \\
\hline $\begin{array}{l}\text { A. femoralis } \\
\text { distal part }\end{array}$ & $\begin{array}{l}\text { On the back. } \\
\text { Knee extended. } \\
\text { Foot rotated } \\
45^{\circ} \text { lateral. }\end{array}$ & 35 & 30 \\
\hline A. poplitea & $\begin{array}{l}\text { On the right side. } \\
45^{\circ} \text { flexion } \\
\text { of the knee. }\end{array}$ & 35 & 25 \\
\hline $\begin{array}{l}\text { A. tibialis ant. } \\
\text { A. tibialis post. } \\
\text { A. peronea }\end{array}$ & $\begin{array}{l}\text { On the back. } \\
\text { Knee extended. } \\
30^{\circ} \text { medial rotation }\end{array}$ & 46 & 40 \\
\hline $\begin{array}{l}\text { A. tibialis ant. } \\
\text { A. tibialis post. } \\
\text { A. peronea }\end{array}$ & $\begin{array}{l}\text { On the right side. } \\
45^{\circ} \text { flexion } \\
\text { of the knee. }\end{array}$ & 44 & 40 \\
\hline $\begin{array}{l}\text { A. metatarsea I } \\
\text { Aa. digitales } \\
\text { pedis }\end{array}$ & $\begin{array}{l}\text { On the back. } \\
\text { Full flexion } \\
\text { of the knee. }\end{array}$ & 48 & 50 \\
\hline $\begin{array}{l}\text { A. tibialis ant. } \\
\text { A. dorsalis pedis } \\
\text { A. tibialis post. } \\
\text { A. plantaris }\end{array}$ & $\begin{array}{l}\text { On the right side. } \\
\text { Slight flexion } \\
\text { of the knee. }\end{array}$ & 50 & 50 \\
\hline
\end{tabular}

Types of calcification: Three types of calcification were distinguished according to Lindbom [15].

Media calcification appears as a more or less con. tinuous line along one or both sides of the artery, and sometimes as a faint band between these lines.

Intima calcification appears as irregular spots or streaks of densities along the longitudinal axis of the artery. Each spot or streak varies greatly in the intensity from one area to another.

Calcification of the elastica interna appears as small elusters or groups of tiny grains in the course of the artery. They are usually only to be seen in the anterior tibial artery, in rare cases also in the posterior one.

All measurements were performed in a series of selected areas, delimited by planes according to easily definable osseous points.

Media calcification was determined by measuring the dotted or continuous lines indicating this type of

1 The x-ray apparatus contained a Müller generator type DA 1000, and a tube of the type XF 2001/10. 
calcification, through a magnifying glass of $4 \mathrm{D}$. The degree of calcification was expressed as the sum of the millimeters measured on both sides of the artery in the area selected.

Intima calcification was determined on drawings made by projecting the film onto paper at a magnification of 2.5 times. The spots were then measured by counting squares of a transparent graph paper placed over them.

Calcifications in the internal elastica were found too small to be measured.

All measurements were done in duplicate. The second measurement was made several weeks after, and without knowledge of, the first one.

\section{Statistical Analysis}

An analysis of variance was performed on some of the calcification values obtained by the two measurements. It was carried out for the sum of intima calcification in the thigh and the calf and for the sums representing media calcification in the thigh, the calf, and the foot. The standard deviation increased with increasing values, and therefore the test was performed in subgroups representing values of different size, and the coefficient of variation was calculated. For intima calcification values the coefficient of variation was $41 \%$ in the group $4-10 \mathrm{~mm}^{2}, 21 \%$ in the group $20-30 \mathrm{~mm}^{2}$ and $9 \%$ in the group $50-75 \mathrm{~mm}^{2}$. Similarly for media calcification the coefficient of variation was in the group $0.25-3.25 \mathrm{~mm}$ calcification $37 \%$ and $38 \%$ for crural and foot arteries respectively. In the group $9.25-12.25 \mathrm{~mm}$ calcification the corresponding values were $22 \%$ and $19 \%$, in the group $18.25-21.25$ they were $23 \%$ and $15 \%$.

The relationship between glucose tolerance and arterial calcification was tested by regression analysis in a computer. The independent variable was the calcification value obtained in each of nine arterial areas or a sum of areas. The dependent variable was the individual blood sugar values obtained during the glucose tolerance test or a value calculated from these. The calculations were performed in each of the age groups, for diabetic men and women, and non-diabetic men and women separately.

The same computer program was used in each of the many regression analyses. In principle the procedure was as follows:

First, the regression lines for the four age groups of the diabetic population were estimated and tested for identity of slope and position. If a common slope could be estimated, this slope was tested for significant deviation from zero. Then the same calculations were performed for the non-diabetic population. Finally, if and only if a common slope for the four age groups in each of the populations could be estimated, the two common slopes were tested for identity of slope and position and for significant deviation from zero [12].

\section{Results}

The average incidence of media calcification in a certain age group was higher for diabetics than for non-diabetics, and higher for men than for women, but none of these differences were statistically significant $(p>0.05)$.

If $70 \mathrm{~mm}$ calcification or more is chosen arbitrarily to express "severe media calcification", this was found in $61 \%$ of the diabetics, as against $16 \%$ of the nondiabetics. This difference is significant $(p<0.05)$.

In the oldest age groups, media as well as intima calcification was significantly more common than in the youngest, both in the diabetic and in the nondiabetic population $(p<0.05)$.

No difference was observed between the occurrence of intima calcification in the diabetic and non-diabetic populations, or among men and women.

The positive correlation of the many regression analyses of the relationship between blood glucose and media calcification is presented in Fig. 1. It appears that the calcification values of a number of arterial areas were positively correlated to four commonly accepted expressions of glucose tolerance, viz. the two-hour blood sugar value, the two-and-a half hour value, the total area under the blood glucose curve, and the area of increase (the definition of these areas is indicated on Fig. 1).

The strongest correlation was found by studying the media calcification in the leg arteries in the nondiabetic group. In this case a statistically significant correlation $(p<0.05)$ was found between the degree of arterial calcification and each of the four glucose values mentioned.

For the lower part of the femoral artery a correlation was found between media calcification and the area of increase in the non-diabetic group.

In the diabetic group, it appears that there is a positive correlation between media calcification in the lower part of the posterior tibial artery and the twohour blood sugar value, and also between the sum of calcification in the foot arteries and the area of increase.

Including all patients, diabeties as well as nondiabetics, only one positive correlation was obtained, namely between calcification in the lower part of the posterior tibial artery and the area of increase.

The positive correlations obtained in the study of the relationship between blood glucose and intima cal. cification were quite different.

In the diabetic group, no correlations were found between intima calcification and the four parameters of glucose tolerance mentioned above. However, a single positive correlation was obtained between intima calcification and a derived expression of the blood sugar values: The sum of calcifications in the thigh and the calf of diabetics was positively correlated to the difference between the highest and the last glucose values on the glucose tolerance curve, and also 
to this difference expressed as a percentage of the highest value.

In the non-diabetic group no positive correlations were found.

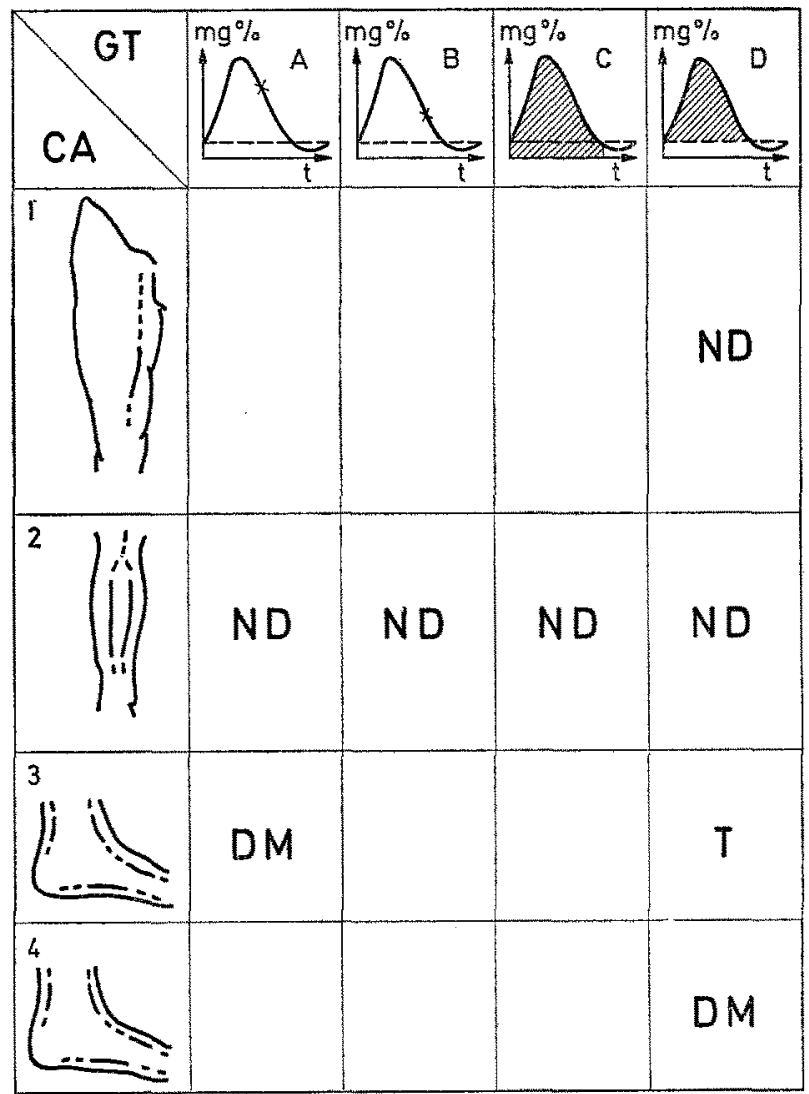

Fig. 1. The positive correlations between media calcification and glucose tolerance

GT: glucose tolerance. CA: media calcification.

1-4: The femoral, the crural and the foot arteries are indicated. The drawn line represent that part of the artery in which the calcification is measured.

A-D: The two-hour value, the two-and-a-half hour value, the total area under the glucose tolerance eurve, and the area of increase. Abcissa: time. Ordinate: $\mathrm{mg} \%$ glucose.

ND: non-diabetics.

DM: diabetics.

$\mathrm{T}$ : all patients.

The analysis including all patients showed only' one significant correlation, namely that between intima calcification in the thigh and the difference between the highest and the last glucose values, expressed as a percentage of the first one.

\section{Discussion}

Radiological intima and media calcification in all parts of the femoral arteria has been quantitated and tested for correlation to glucose tolerance among diabetics and non-diabetics.
A fundamental difference was found between the two types of calcification.

Intima calcification in diabetics and non-diabetics was not correlated to glucose tolerance expressed by the usual four parameters, viz. the two-hour blood sugar value, the two-and-a-half hour value, the total area under the blood sugar curve, and the increase in area. Further, the incidence of this type of calcification was the same for diabetics and non-diabetics in all parts of the femoral arteria.

Media calcification in the crural arteries of nondiabetics is correlated to the four, usual parameters of glucose tolerance mentioned above. In the stperficial femoral artery, media calcification is correlated to one of those parameters. Media calcification in foot arteries was not correlated to glucose tolerance.

The same correlations may have been expected between media calcification and glucose tolerance in the diabetic population, but this was not the case. The reason for this is probably that oral glucose tolerance does not express precisely the degree of diabetes or diabeticity in patients with clinical diabetes.

It is well known that "arteriosclerosis" and diabetes are related somehow. Several investigations have pointed out that radiological calcification in extremital arteries is more common and more pronounced in diabetics than in non-diabetics $[4,5,18]$.

The pathological anatomical distinction between media and intima calcification is due to Monckeberg [17], and he pointed out already at the turm of the century that such a distinction was possiblo also roentgenologically [17]. Radiological studies of arterial calcification up to the 1950 's did not, however, distinguish between spotty and linear calcification. Lindbom [15] and Barnum [2] have shown that such a distinction can be made, and that it is in agreement with the usual pathological anatomical distinction between atherosclerosis and media selerosis.

Ferrier has shown that media calcification is the characteristic arterial lesion in diabetics [10], and Juel Christensen found that medial calcification is much more frequent among young diabetics than among young non-diabetics [7].

The relation of glucose tolerance to ischaemic arterial disease, especially in coronary arteries, has been investigated of Keen [13] and Wahlberg [19]. They found that patients with ischaemic arterial disease had a low tolerance for glucose.

Pantly based on Lindbom's investigation [15], where low voltage roentgenograms were compared with arteriographies, it has been thought that only intima calcification affects the arterial lumen. The high incidence of occlusive arterial disease, gangrene etc. among diabetios [3] does not seem to harmonize with the findings in this study: A correlation between glucose tolerance and media calcification, but no correlation to intima calcification. It has been shown recently, however, that media calcification is often followed by intima thickening in foot arteries [11], and 
it seems reasonable to assume that media calcification deprives the artery of some of its elasticity. Juel Christensen [8] found an association in diabetic persons between media calcification and decreased, postischaemic peak flow in the foots, and perhaps the caleification might contribute to the increased peripheral resistance.

\section{References}

1. Allan, E.V.: Peripheral vascular disease, p. 280. Philadelphia: Saunders 1962.

2. Barnum, E.N.: The roentgenografic differentiation of peripheral arteriosclerosis. Amer. J. Roentgenol. 68, $619-626$ (1952).

3. Bell, E.T.: Ineidence of gangraena of the extremities in nondiabetic and diabetic persons. Arch. path. 49, $469-473(1950)$.

4. Bowen, B.D.: A study of the lower extremities in diabetes as compared with non-diabetic states, from the standpoint of x-ray findings, with particular reference to the relationship of arteriosclerosis and diabetes. Buffalo general Hosp. Bull. 2, 35-41 (1924).

5. - Arterioselerosis and diabetes; including a roentgenological study of the lower extremities. Buffalo general Hosp. Bull. 5, 31-43 (1927).

6. Caird, F.I.: Diabetes and the eye, p. 76. Oxford: Blackwell scientific publications 1969.

7. Christensen, J.: Muscle blood flow, measured by Xenon ${ }^{133}$ and vascular calcifications in diabetics. Acta med. scand. 183, $449-464$ (1968).

8. - Spontaneous variation in resting blood flow, postischaemic peak flow and vibratory perception in the feet of diabetics. Diabetologia 5, 171-178 (1969).
9. Fagerberg, S.: Diabetic neuropathy. Acta med. seand. 164, 345 (1959).

10. Ferrier, T.M.: Radiologically demonstrable arterial caleification in diabetes mellitus. Aust. Ann. Med. 13, $222-228$ (1964).

11. - Comparative study of arterial disease in amputated lower limbs from diabetics and non-diabetics. Med. J. Aust. 1, 5-11 (1967).

12. Hald, A.: Statistical theory with engineering applications, chap. 18, sec. 9, 4. edition (1960). John Wiley and Sons, Ine.

13. Keen, H.: Blood sugar and arterial disease. Lancet 1965 II, $505-508$.

14. Ledet, T.: Histological and histochemical changes in the coronary arteries of old diabetic patients. Diabetologia 4, 268-272 (1968).

15. Lindbom, A.: Arterioselerosis and arterial thrombosis in the lower limbs. Acta radiol. suppl. 80, 38-48 (1950).

16. Lundbæk, K.: Diabetic retinopathy in newly diagnosed diabetes mellitus. Acta med. scand. 152, 53 (1955).

17. Mønckeberg, J.G.: Über die reine Mediaverkalkung der Extremitätenarterien und ihr Verhalten zur Arterioselerose. Virchows Arch. f. pathol. Anat. 171, $141-167$ (1904).

18. Morrison, L. B. : Caleification of the vessels in diabotes. J. Amer. med. Assoc. 92, 1424-1426 (1929).

19. Wahlberg, F. : Intravenous glucose tolerance in myocardial infarction, angina pectoris and intermittent claudication. Acta med. scand. 180 suppl. 453, 85-87 (1966).

Dr. B. Neubaner

Second Clinic of Internal Medicine

Kommune Hospitalet

Aarhus University School of Medicine

Aarhus, Denmark 